\title{
Critérios para a elaboração de uma política criminal: bem-estar geral e igualdade
}

Tiago Ivo Odon'

\begin{abstract}
Resumo
O presente trabalho tem por objetivo realizar um exercício argumentativo sobre os nortes valorativos a serem considerados para a elaboração de uma política pública. Assim, com base em dois critérios presentes na economia política e na filosofia política - os valores bem-estar geral e igualdade, constantes do utilitarismo de John Stuart Mill e da teoria de justiça de John Rawls, respectivamente -, pretende-se analisar a forma diferenciada com que ambos podem orientar uma política criminal.
\end{abstract}

Palavras-chave: Bem-estar. Igualdade. Eficiência. Justiça. Política criminal.

\section{Política criminal e política pública}

Toda norma jurídica nasce de uma decisão política. Eugenio Zaffaroni define política criminal como a ciência ou a arte de selecionar os bens (ou direitos) que devem ser tutelados jurídica e penalmente e de escolher os caminhos para efetivar tal tutela. ${ }^{2}$ Já as políticas públicas, na definição de Maria das Graças Rua, compreendem o conjunto das decisões e das ações relativas à alocação imperativa de valores. ${ }^{3}$ Dado que o direito penal é um instrumento jurídico de ultima ratio,

\footnotetext{
${ }^{1}$ Advogado e consultor legislativo do Senado Federal; graduado em Direito pelo Centro de Ensino Universitário de Brasília e em Relações Internacionais pela Universidade de Brasília; especialista em Direito Penal e Processual Penal pela Universidade Cândido Mendes; mestre em Direito e Políticas Públicas pelo Centro de Ensino Universitário de Brasília. Professor-tutor do Instituto Legislativo Brasileiro.

${ }^{2}$ ZAFFARONI, Eugenio R.; PIERANGELI, José H. Manual de direito penal brasileiro: parte geral. 4. ed. São Paulo: Revista dos Tribunais, 2002. p. 132.

${ }^{3}$ RUA, Maria das Graças. Análise de políticas públicas: conceitos básicos. In: RUA, Maria das Graças; CARVALHO, Maria Izabel V. (Org.). O estudo da política: tópicos selecionados. Brasília: Paralelo 15, 1998. p. 232.
} 
ou seja, só deve ser usado pelo Estado quando os outros ramos do direito (direito civil, administrativo etc.) se mostrarem inadequados e ineficazes para reprimir e prevenir a ameaça ao bem jurídico em questão, a seleção de bens (como vida, patrimônio, saúde etc.) e a escolha do caminho de tutela estatal - criminalização da ofensa ao bem, a quantidade de pena etc. - traduzem alocação de valores.

Conforme Eugenio Lahera, parte fundamental da ação de governo refere-se ao desenho, à gestão e à avaliação das políticas públicas; ou seja, os governos são instrumentos para a realização de políticas públicas. ${ }^{4}$ Lahera aponta várias características de uma boa política pública, entre elas: critérios para a análise do custobenefício social; análise do benefício social marginal em relação a outras políticas; funcionalidade dos instrumentos etc. Algumas dessas questões têm ganhado um novo relevo na literatura jurídico-criminal, particularmente com a escola da Law and Economics, dos Estados Unidos da América.

A preocupação do presente artigo é com a decisão política a respeito da alocação de valores, isto é, com o desenho da política, mais especificamente, com o norte valorativo que guia a concepção da política na tomada de decisão. A filosofia político-econômica tem oferecido elementos importantes de análise de políticas públicas, os quais orientam a decisão política a respeito da alocação imperativa de valores. Lahera, por exemplo, identifica, na filosofia político-econômica, alguns critérios para se analisar uma política pública, e, nessa perspectiva, toma como referência Pareto, Amartya Sen e John Rawls. A descrição de Lahera é breve e, algumas vezes, imprecisa. Não obstante, nós a usaremos como ponto de partida, acrescentando-lhe outros critérios (como os de Kaldor-Hicks ${ }^{5}$, Hand ${ }^{6}$ e Coase ${ }^{7}$ ) para focar os dois que constituem o objeto de análise deste texto: o critério de bemestar do utilitarismo e o critério de igualdade de Rawls.

O objetivo deste artigo não é avaliar uma política pública, levantar questões sobre os custos de implementação, atores envolvidos etc. O objetivo é, com base em modelos que simplificam a realidade, realizar um exercício argumentativo sobre

\footnotetext{
${ }^{4}$ LAHERA, Eugenio. Política y políticas públicas. Brasília: CEPAL, 2004. p. 7. (Série Políticas Sociales, n. 95).

${ }^{5}$ Dos economistas Nicholas Kaldor e John Hicks.

${ }^{6}$ Do juiz norte-americano Billing Learned Hand.

${ }^{7}$ Do economista britânico Ronald H. Coase.
} 
os nortes valorativos a serem considerados para a tomada de uma decisão política, independentemente dos constrangimentos da aplicação da política em si. Assim, pretendemos focar, como já explicitado, dois critérios - os valores bem-estar geral e igualdade - e analisar a forma diferenciada a que ambos podem recorrer, quanto a orientar uma política criminal.

\section{Critérios de filosofia político-econômica}

Eficiência é um termo caro tanto para o direito quanto para a economia, e fundamental para a elaboração de uma política pública. Eficiência pode ter diferentes significados. "Eficiência alocativa”, por exemplo, refere-se à produção certa ou adequada de determinada quantidade de produto ou serviço. Relacionase com a lei básica de oferta e demanda e preocupa-se com a oscilação de preços no mercado. "Eficiência produtiva", por outro lado, refere-se à produção de resultados ao menor custo possível. ${ }^{8} \mathrm{O}$ termo pode ser usado com diferentes fins. Por exemplo, Pareto e Kaldor-Hicks não concordam entre si quanto ao que seria uma distribuição eficiente de bens.

Na mudança de uma situação de distribuição de bens, se as pessoas envolvidas melhoram de situação e ninguém piora, a realocação é considerada "Pareto superior". Dada essa redistribuição, caso não possa haver uma realocação sem que ao menos uma pessoa seja prejudicada, tal situação é considerada "Pareto ótimo". A eficiência tem outro sentido no modelo de Kaldor-Hicks. Para a distribuição ser eficiente, as pessoas que se beneficiam com a realocação de bens teriam de ser beneficiadas a ponto de poderem compensar os que foram prejudicados.

Poderíamos trocar o termo "eficiência” nesses modelos por "justiça”, para trazer a análise para o âmbito do direito. Assim, podemos ter critérios variados para avaliar a justiça de uma distribuição. Entre os critérios de filosofia políticoeconômica disponíveis, Lahera cita Pareto, Amartya Sen e John Rawls. Para otimizar a análise, acrescentaremos outros: os de Kaldor-Hicks, já antecipado, e os de Hand e Coase.

${ }^{8}$ HARRISON, Jeffrey L. Law and economics in a nutshell. 2. ed. Florida: West Group, 2000. p. 29. 
Segundo o "ótimo de Pareto", na rápida descrição de Lahera, o único critério de melhoria social dá-se quando uma situação alternativa aumenta a satisfação de alguns, sem diminuir a dos outros. Na verdade, essa seria uma situação "Pareto superior", que, como visto, se dá quando alguns melhoram e ninguém piora de situação com a mudança provocada pela implementação da política pública. A situação "Pareto ótima" é aquela em que os recursos estão distribuídos de tal forma que não podem ser realocados sem que alguém seja prejudicado. ${ }^{9}$

A crítica que Lahera dirige a esse abordagem é que as comparações interpessoais de satisfação ou de utilidade não têm bases científicas. De fato, o utilitarismo supõe que os níveis de bem-estar individual sejam comparáveis, de modo a tornar possível a ordenação dos níveis de utilidade total, de acordo com as várias escolhas de programas sociais. ${ }^{10}$

O problema da aplicação de Pareto às políticas públicas é que ela pode levar a ações governamentais limitadas, uma vez que todos teriam de concordar com a política. Uma alternativa seria o equilíbrio de Kaldor-Hicks (conhecido, também, como "maximização de bem-estar"). Para que a situação seja eficiente nesse modelo, como antecipado, os indivíduos beneficiados com a realocação de recursos proporcionada pela política pública teriam de ser, suficientemente, beneficiados, a ponto de poderem compensar aqueles que foram prejudicados. Tal compensação é potencial, e não factual. Esse é um porém importante. ${ }^{11}$

Há outros critérios que, também, associam eficiência à maximização do bem-estar, como o Teorema de Coase. Em termos gerais, numa sociedade em que os direitos de propriedade estão bem definidos e os custos de transação são baixos, o bem deve terminar nas mãos de quem o valora mais. Isso significa que o Estado, por meio de políticas públicas e da legislação, deveria interferir o mínimo possível na sociedade, isto é, constranger o mínimo possível a livre negociação entre as partes, pois ele sempre acaba por aumentar os custos das transações sociais (com normas que distribuem ônus e bônus desigualmente, com limitações à iniciativa

\footnotetext{
9 "In short, an allocation is Pareto superior if achieving it means at least one person is better off and no one is made worse off. It is Pareto optimal if any movement from that allocation would make at least one person worse off". HARRISON, Jeffrey L. Law and economics in a nutshell. 2. ed. Florida: West Group, 2000. p. 33.

${ }^{10}$ DWORKIN, Ronald. Uma questão de princípio. 2. ed. São Paulo: M. Fontes, 2005. p. 387.

${ }^{11}$ Ibidem, p. 35.
} 
privada, taxas, certidões, insegurança jurídica, burocracia administrativa etc.), o que significa, ao final, a geração de ineficiência na sociedade.

Outro critério é a Fórmula de Hand, que pode atuar para avaliar responsabilidades. Nessa perspectiva, a responsabilidade é uma função de três variáveis: a probabilidade do dano (P), a quantidade do dano a ocorrer (L) e o custo da prevenção (B). P x L (P multiplicado por L) é o dano esperado. Assim, pela Fórmula de Hand, se PL > B, o ofensor é responsável; se $\mathrm{PL}<\mathrm{B}$, o ofensor não é responsável. Significa dizer que a parte é culpada sempre que o dano pudesse ter sido evitado a um custo mais baixo.

Todos esses critérios citados, excluindo-se o de Pareto, ${ }^{12}$ podem ser incluídos no critério geral de maximização de bem-estar, ou, simplesmente, critério de bem-estar geral. É o critério clássico do utilitarismo. Esses critérios não estão preocupados com as pessoas consideradas individualmente, mas com uma situação final julgada justa ou eficiente. Ou seja, foca a maximização do bem-estar social total. A sociedade ganha quando um bem está nas mãos de quem o valora mais, a sociedade ganha quando as pessoas podem evitar danos, se a prevenção custa menos que a reparação, não importando o bem-estar individual das pessoas envolvidas em cada caso concreto.

Lahera faz referência, em segundo lugar, a Amartya Sen, que não vê, no bemestar, a tradução da soma das utilidades agregadas. mas, sim, a representação das liberdades de que o indivíduo, efetivamente, dispõe, por meio do uso dos direitos e das oportunidades ao seu alcance. A obtenção da verdadeira liberdade dependeria, portanto, de uma combinação entre direitos e capacidade de gozo. ${ }^{13}$ Ou seja, não se deve levar em consideração apenas a mera distribuição de bens, conforme os modelos de Pareto e Kaldor-Hicks, por exemplo, mas, também, a capacidade de as pessoas usufruírem desses bens.

${ }^{12}$ Mesmo considerando que Pareto se situa dentro da tradição utilitarista, por trabalhar com a idéia de utilidade, nós o situaremos em outra abordagem, que alguns autores, como Dworkin, chamam de "utilitarista igualitária". Como colocou o próprio Dworkin, o "utilitarismo é realmente duas teorias diferentes, ou, melhor, há duas maneiras diferentes de ser um utilitarista” DWORKIN, Ronald. Uma questão de princípio. 2. ed. São Paulo: M. Fontes, 2005. p. 409-410. O objetivo é apenas diferenciar os que focam a utilidade considerada individualmente, pessoa a pessoa, e os que focam a utilidade total, num determinado arranjo distributivo, vendo as pessoas como somas agregadas.

${ }^{13}$ SEN, Amartya. Desenvolvimento como liberdade. São Paulo: Cia das Letras, 2000. p. 72-108. 
Em ataque a John Rawls, que usa um modelo semelhante ao de Pareto, Sen afirma que não bastaria uma simples dotação de bens primários ("direitos, liberdades e oportunidades, assim como renda e riqueza"14), que seriam garantidos para as pessoas exercerem seu papel no sistema político. Para ele, as capacidades de gozo não são garantidas se não houver uma relação entre tais bens e as pessoas, dadas as diferenças interpessoais. A preocupação de Sen é de ordem prática: do que adianta garantir determinados direitos a certas pessoas - por meio de uma política pública que gerará uma redistribuição justa, seja aos olhos de Pareto ou de Kaldor-Hicks - se elas não possuem condições econômicas de exercitá-los? ${ }^{15}$

Por fim, Lahera cita Rawls, cuja teoria prevê uma dotação de bens primários para que as pessoas satisfaçam seus planos de uma vida racional ${ }^{16}$. Para Rawls, a justiça de um esquema social depende, essencialmente, do modo como se atribuem direitos e deveres fundamentais, das oportunidades econômicas e das condições sociais que existem nos vários setores da sociedade ${ }^{17}$. Nesses termos, a justiça verifica-se quando observados, serialmente, dois princípios: (1) a igualdade na atribuição de deveres e de direitos básicos; e (2) a desigualdade econômica e social, apenas se resultar em benefícios compensatórios para cada um e, particularmente, para os menos favorecidos.

Harrison percebe uma afinidade desse arranjo de Rawls com a eficiência de Pareto: "os que são beneficiados apenas se beneficiam se aqueles situados no fundo da distribuição também se beneficiam”."18

\footnotetext{
${ }^{14}$ RAWLS, John. Uma teoria da justiça. 2. ed. São Paulo: M. Fontes, 2002. p. 98.

${ }^{15}$ No arranjo de Rawls, a justiça do resultado deriva da justiça no procedimento. Sua teoria traduz uma "justiça procedimental pura" Ibidem, p. 89-95. As capacidades são "dados" na teoria de Rawls (são pressupostos). A preocupação de Rawls com a capacidade econômica - foco de Sen - está subordinada ao primeiro princípio de justiça, que trata das liberdades jurídicas. Sen critica o arranjo segundo o qual "liberdades formais pessoais, como alguns direitos políticos e civis básicos [...] não podem ser de modo algum comprometidos pela força das necessidades econômicas". E pergunta-se: "Por que o peso das necessidades econômicas intensas, que podem ser questões de vida ou morte, deveria ser inferior ao das liberdades formais pessoais?” SEN, Amartya. Desenvolvimento como liberdade. São Paulo: Cia das Letras, 2000. p. 83.

16 "O bem é a satisfação de um desejo racional". RAWLS, op. cit., p. 98.

${ }^{17}$ Ibidem, p. 8.

${ }^{18}$ No original: "those who become better off could only do so if those at the bottom of the distribution are also made better off". HARRISON, Jeffrey L. Law and economics in a nutshell. 2. ed. Florida: West Group, 2000. p. 301.
} 


\section{Os critérios de bem-estar e de igualdade}

Preferindo o termo "justiça" a "eficiência", para trazer a análise para o âmbito do direito, este trabalho explorará dois critérios de justiça: o da igualdade, ${ }^{19}$ relacionado com o modelo de Pareto e os princípios de Rawls, e o do bem-estar geral, relacionado com os modelos de Kaldor-Hicks, de Coase e de Hand.

Este trabalho conjuga alguns pressupostos metodológicos para a análise tanto do critério de bem-estar quanto do critério de igualdade. O primeiro pressuposto é que os indivíduos são maximizadores de interesses. Isso significa que trabalhamos, aqui, com a racionalidade instrumental clássica: a racionalidade que busca adequar meios e fins a uma análise de relação custo-benefício. Esse tipo de racionalidade, que é teleológica, toma como base que os indivíduos não se engajarão em ações que pareçam inconsistentes. O segundo pressuposto é que a justiça é uma questão de distribuição de bens, bens aqui considerados de forma ampla, abrangendo direitos. ${ }^{20} \mathrm{O}$ terceiro pressuposto é que não há diferença entre a soma que as pessoas estariam dispostas a pagar por algum bem que não possuem e a soma que receberiam em troca desse bem se já o possuíssem. Finalmente, o quarto pressuposto é o de que o mercado é um regulador de preços eficiente.

O critério de bem-estar geral é o critério utilitarista clássico. Tanto a teoria de justiça de Rawls quanto o utilitarismo trabalham no campo da escolha racional, idéia esta subjacente à idéia liberal clássica do contrato social, que funda o Estado moderno. Ambos encontram-se na mesma tradição liberal. A razão básica para se abrir mão de certas liberdades e constituir o Estado reside na pressuposição de que todos estariam melhor na nova situação. ${ }^{21}$ Partindo da eficiência de Pareto, só pode

${ }^{19}$ Rawls prefere "eqüidade" (fairness). Como fairness é um termo de uso mais corrente nos sistemas jurídicos da common law, preferimos "igualdade", que, aliás, seria o norte valorativo da teoria de Rawls, conforme já esclareceu Ronald Dworkin, "justice as fairness rests on the assumption of a natural right of all men and women to equality of concern and respect [...]". DWORKIN, Ronald. The original position. In: DANIELS, Norman (Ed.). Reading Rawls: critical studies on Rawls'A theory of justice. California: Stanford University Press, 1975. p. 51.

${ }^{20}$ Há divergências quanto à teoria de justiça de Rawls ser uma teoria distributiva. No entanto, para fins didáticos, pressupomos aqui, até para viabilizar as comparações, que seja.

${ }^{21}$ Montesquieu resumiu bem essa idéia ao dizer que "A liberdade é o direito de fazer tudo o que as leis permitem; se um cidadão pudesse fazer tudo o que elas proíbem, não teria mais liberdade, porque os outros também teriam tal poder". MONTESQUIEU. O espírito das leis. Brasília: Universidade de Brasília, 1995. p. 186. 
haver Estado se todos consentirem ("pacto de consentimento", de John Locke), o que está muito próximo da idéia de consentimento de Rawls. Partindo da eficiência de Kaldor-Hicks, só pode haver Estado se aqueles que se beneficiarem compensarem aqueles que se prejudicarem, idéia própria do utilitarismo de John Stuart Mill (a idéia de "maximização da utilidade" é substituída pela idéia de "maximização do bem-estar"22).

Ou seja, as propostas do utilitarismo de Mill e de justiça de Rawls distinguem-se da seguinte maneira: enquanto o utilitarismo permite que indivíduos sejam prejudicados à medida que o bem-estar geral aumenta (interessa, portanto, um ganho líquido de bem-estar), a justiça como eqüidade, de Rawls, só permite isso se esses prejudicados também forem, de alguma forma, proporcionalmente, beneficiados. ${ }^{23}$ Neste último caso, a justiça consiste na distribuição que implica tratamento igual às pessoas (ou em melhoria de Pareto nessa distribuição) e nega outro valor independente nesse cálculo. No primeiro caso, o bem-estar total é considerado um valor independente, de modo que a sua redução, mesmo que necessária para a obtenção de outro valor, é tida como uma perda de justiça.

Esses dois critérios, ao serem considerados para uma decisão política, podem levar a caminhos diferentes de política pública na área criminal.

\subsection{0 critério de bem-estar geral}

De acordo com Mill, a solução justa é aquela que maximiza o bem-estar ou a felicidade geral. A felicidade está na obtenção do útil, ou seja, no afastar-se da dor e aproximar-se, o máximo possível, do prazer, do bem-estar. ${ }^{24}$ Portanto,

${ }^{22}$ HARRISON, Jeffrey L. Law and economics in a nutshell. 2. ed. Florida: West Group, 2000. p. 297-298.

${ }^{23}$ O critério de Rawls é rigoroso: "o que o princípio da diferença realmente exige é que durante um intervalo apropriado de tempo as diferenças de renda e riqueza geradas pela produção do produto social sejam tais que se as expectativas legítimas dos mais favorecidos fossem menores, as dos menos favorecidos também seriam menores”. RAWLS, John. Justiça como eqüidade. São Paulo: M. Fontes, 2003. p. 226.

24 "Segundo o Princípio da Maior Felicidade [ou da Maior Utilidade] [...], o fim último [...] é uma existência isenta tanto quanto possível da dor, e tão rica quanto possível em deleites, seja do ponto de vista da quantidade ou da qualidade." MILL, John Stuart. Utilitarismo. São Paulo: M. Fontes, 2000. p. 194. 
entre várias opções disponíveis, a solução justa verifica-se quando se obtém o maior ganho de felicidade para a sociedade como um todo. Esse é o dever-ser de toda ação política, para Mill. Assim, a lei e as políticas públicas deveriam "pôr o mais possível a felicidade ou o interesse de cada indivíduo em harmonia com os interesses do todo.".25

Por esse critério, uma política criminal poderia ser usada para garantir bem-estar geral, o que inclui a redução da quantidade de uma determinada atividade julgada ineficiente, a moldagem de preferências, a canalização forçada de transações para o mercado e a prevenção de externalidades (custos sociais altos). Assim, por exemplo, o bem-estar social é maximizado quando recursos escassos estão nas mãos de quem pagaria mais do qualquer outro por eles (Teorema de Coase) ou quando as pessoas sempre investem na prevenção de incidentes, se tais custos são menores que a probabilidade/quantidade de ocorrência ( $\mathrm{PL}<\mathrm{B}$ (Fórmula de Hand)). Se os fatos ocorrem de forma diferente, isto é, gerando o que se considera ineficiência global (uma situação de injustiça social, portanto), o direito pode ser usado para reequilibrar essas relações. Uma lei, oriunda de uma política pública que levou em consideração tais elementos de análise, determinaria o direito/dever de cada parte.

Uma questão hipotética de política criminal poderia ser a seguinte: criminalizar ou não o furto? Em relação a questões patrimoniais, há dois métodos tradicionais de proteção de direitos: a regra da propriedade (property rule) e a regra da responsabilidade (liability rule). A aplicação da primeira é recomendada quando os custos de transação são baixos, e da segunda, quando altos. Assim, a regra de responsabilidade protege, obrigando o indivíduo que lesou outro a compensar o dano sofrido. Dado que os custos de uma transação prévia seriam muito altos, a proteção opera após o fato, obrigando a compensação. A regra de propriedade, por sua vez, obriga uma transação prévia.

Suponhamos, assim, que o furto não seja previsto como crime, num determinado ordenamento jurídico, e que uma pessoa possua um carro avaliado pelo mercado em R \$ 5 mil. Todavia, ela não aceitaria menos que R 7 mil pelo carro, considerando o seu valor afetivo pelo bem. A previsão de uma regra de respon-

${ }^{25}$ MILL, John Stuart. Utilitarismo. São Paulo: M. Fontes, 2000. p. 202-203. 
sabilidade significaria que uma pessoa poderia tomar esse carro sem permissão e compensar o proprietário, depois, pelo preço de mercado, ou seja, por $\mathrm{R} \$ 5$ mil. Isto é, a transação resultaria numa situação final em que o bem passaria a ser da propriedade de quem o valora menos. A nova alocação seria injusta.

Por outro lado, se a propriedade do bem estivesse protegida por uma regra de propriedade, o carro não seria transferido sem o prévio consentimento do vendedor. Um acordo sobre o preço precederia a transferência. Essa segunda alocação é mais eficiente do que a primeira. O ponto é: o direito civil é suficiente para garantir que essa eficiência tenda sempre a ocorrer? Como os custos de transação da primeira alocação são mais baixos, apesar de o resultado ser injusto, o direito civil não seria instrumento jurídico suficiente. Assim, o direito penal pode ser usado estrategicamente pelo Estado para forçar que a segunda alocação tenda sempre a acontecer, criminalizando a transferência não-consentida (furto). A aplicação de uma pena de privação da liberdade seria eficaz nesse sentido. ${ }^{26} \mathrm{Ou}$ seja, o ladrão, passando a correr o risco de perder a liberdade, se sentiria forçado a pagar pelo carro um preço superior ao valor de mercado (os R $7 \mathrm{mil}$ ). Ou seja, o direito penal pode transformar uma regra de responsabilidade em regra de propriedade, dado que a previsão da conduta como crime faz diminuir os custos da transação para a segunda situação.

Portanto, o critério de eficiência pode ser usado na elaboração de uma política criminal para crimes patrimoniais, que envolvem ganhos de utilidade transacionáveis para o agente criminoso. Em relação aos bens jurídicos não-transacionáveis, como vida, saúde, integridade física etc., a aplicação do critério de bem-estar é mais limitada, mas poderia ser feita para levar o direito penal a criar uma regra de inalienabilidade; ou seja, cominar-se-ia, abstratamente, uma pena tão alta, tornando o custo de transação tão alto, que se eliminaria qualquer possibilidade racional de tais transferências terem lugar no mercado (como venda de órgãos humanos, trabalho escravo etc.). O direito penal estaria protegendo as pessoas, em geral, dessas transferências não-consentidas. $\mathrm{O}$ fundamento racional disso seria o propósito de se evitarem externalidades.

\footnotetext{
${ }^{26}$ Aqui, obviamente, entraria a questão da necessidade de certa quantidade de pena, que deveria ser alta o suficiente para forçar a segunda alocação. Uma pena de multa baixa, por exemplo, não teria esse efeito, se comparada com uma pena de prisão, ou uma pena de prisão baixa poderia ser menos constrangedora do que uma pena de prisão alta.
} 
Por exemplo, o porte de arma de fogo. Criminalizar, para o cidadão comum, com uma rígida política pública de desarmamento ou apenas prever como um ilícito administrativo? Quando a probabilidade de um incidente ocasionado pelo uso de uma arma de fogo é multiplicado pelo dano, e o resultado é comparado com o custo da prevenção, o portador da arma sempre aparecerá como responsável (PL > B). Ou seja, não é possível usar a Fórmula de Hand. Pelo Teorema de Coase, o direito deve terminar nas mãos de quem o valora mais, ou seja, do portador da arma! Então, não é possível, também, usar o Teorema de Coase. Nesse caso, já que lidamos com um bem não-transacionável, o direito penal é usado para se evitar um alto custo social (a falta de paz social, insegurança geral etc.). A lei penal, nesses casos, ao aumentar, expressivamente, o preço do bem, procura desestimular transações envolvendo tal bem no mercado. Assim, pode lançar mão de penas altas, inafiançabilidade, retirada de benefícios de execução penal (progressão de regime, por exemplo), entre outros recursos.

Por fim, em relação ao critério de bem-estar geral, conviria mencionar a questão da moldagem de preferências. Uma regra econômica básica é que alterações de preço de um bem não resultam, necessariamente, na mudança de preferências pessoais. Assim, a queda da demanda pelo bem não significa que ele se tenha se tornado menos útil ou menos satisfatório para as pessoas, mas, apenas, que a substituição por um bem equivalente e mais barato se tornou mais racional e atrativa. Uma das conseqüências do direito penal pode ser justamente a mudança da preferência. O estigma associado à conduta criminosa (efeitos da sentença condenatória, como perda da liberdade, perda de direitos políticos, perda do cargo público etc.) é consistente, conforme Harrison, com mudanças de curvas de demanda. ${ }^{27}$ Assim, o direito penal poderia ser usado, por exemplo, com o propósito de forçar mudança de preferência por bens "piratas" para bens legais.

\subsection{0 critério de igualdade}

Podemos chegar a decisões de política criminal bem distintas se usarmos, por outro lado, o critério de justiça de Rawls. Ele afirma que bem-estar geral não garante justiça e, ainda, que cada membro da sociedade é visto como possuidor

\footnotetext{
${ }^{27}$ HARRISON, Jeffrey L. Law and economics in a nutshell. 2. ed. Florida: West Group, 2000. p. 207.
} 
de uma inviolabilidade fundada na justiça, ou, como preferem outros, no direito natural, que nem mesmo o bem-estar de todos os outros poderia anular. Assim, a justiça nega que a perda da liberdade para alguns se justifique por um bem maior partilhado por outros. Portanto, numa sociedade justa, prossegue Rawls, as liberdades básicas são tomadas como pressupostos, e os direitos assegurados pela justiça não estão sujeitos à negociação política ou ao cálculo dos interesses sociais ${ }^{28}$. Em outras palavras, o critério de justiça utilitarista, sozinho, não pode servir como uma concepção de justiça, sendo preciso "completá-lo de alguma forma"29. Rawls, assim, idealiza um novo tipo de contrato social.

Rawls cria uma situação factual hipotética ("posição original", espécie de "estado de natureza", momento prévio à fundação da sociedade civil propriamente dita), para dela derivar normas. O "estado de natureza" em Rawls, todavia, não é uma mera subtração, como em Hobbes, Locke e Rousseau, nem se chega aos direitos por mera dedução/indução lógica. Os indivíduos nele situados possuem conhecimentos gerais da sociedade civil, mas desconhecem as posições sociais que ocupam e os dotes naturais que possuem (estão sob um "véu de ignorância"). Esses indivíduos têm poder de escolha, e, na concepção de Rawls, tenderiam a fazer uma escolha, ponderando custos e benefícios, que se traduziria nos dois princípios de justiça que propõe (já descritos acima, no item 2, Critérios de filosofia políticoeconômica): (1) a igualdade na atribuição de deveres e direitos básicos; e (2) a desigualdade econômica e social apenas se resultar em benefícios compensatórios para cada um e, particularmente, para os menos favorecidos (chamado de "princípio da diferença”). A sociedade, vista assim, como um sistema de cooperação social, é fundada sobre esses princípios de justiça.

Importante perceber que Rawls fornece um critério interessante para a análise de uma política pública: a posição original. Antes da tomada de decisão, os atores envolvidos na questão fariam um exercício hipotético, retirando-se dos papéis sociais que ocupam e despindo-se dos talentos naturais que, eventualmente, possuam, para avaliar qual seria a decisão mais justa. Assim, os atores fariam um prévio exercício mental, com base no qual teriam de decidir, incluindo a possibilidade de poderem estar em qualquer dos lados da questão objeto da política.

\footnotetext{
${ }^{28}$ RAWLS, John. Uma teoria da justiça. 2. ed. São Paulo: M. Fontes, 2002. p. 30.

${ }^{29}$ Ibidem, p. 75.
} 
Garantida a igualdade de direitos e deveres, passar-se-ia à adoção do princípio da diferença, compensando os menos favorecidos. Esse procedimento, na análise de Rawls, garantiria resultados justos, apesar de, na visão utilitarista, ao custo de se gerar redução da utilidade total.

Voltando ao exemplo inicial da criminalização ou não do furto, a idéia de justiça de Rawls não é a de que o bem deva estar com quem o valora mais, mas que, na transferência, o ganho deva acontecer para ambos, compensando-se o menos favorecido. Assim, se o comprador não puder oferecer mais do que R\$ 6 mil pelo carro, por possuir um estoque de bens inferior ao que possui o vendedor, a transação deve dar-se em R\$ 6 mil, por medida de eqüidade, e não de utilidade total, pois a situação de ambos é melhorada (no caso do vendedor, porque vende acima do preço de mercado; e no do comprador, porque adquire um bem de que necessita) e compensa o menos favorecido, já que o carro será vendido a preço abaixo do que o vendedor atribuiu ao veículo. Estaríamos, aqui, sob a regra de propriedade.

O potencial comprador, da mesma forma, poderia, dado o baixo custo da ação, furtar o veículo e compensar o vendedor a preço de mercado, ou seja, R\$ 5 mil (regra de responsabilidade). Objetivando evitar essa segunda alocação, o Estado usaria o direito penal para forçar o acordo de preços, aumentando o custo do ato de furto. Todavia, a simples aplicação do princípio de bem-estar não seria suficiente para garantir a justiça da transação sob a regra da propriedade. $\mathrm{O}$ direito penal não poderia ser usado, apenas, com o fim de se forçar o acordo de preço, criminalizando a transferência não-consentida, mas teria de ser usado de modo que o acordo de preço representasse um ganho para ambos e compensação para o menos favorecido (uma situação Pareto superior). Ou seja, a estratégia da política não pode pretender, simplesmente, forçar a solução mercadológica, como no exemplo do item 3.1. Nessa perspectiva, pelo critério de justiça de Rawls, o direito penal também deve forçar a realização de uma transferência eqüitativa de direitos, aumentando o custo da transação para quem quiser operar com a lógica da utilidade total. Por exemplo, isso poderia ser feito criando-se circunstâncias agravantes ou qualificadoras para quem não operasse segundo o critério de igualdade.

É difícil usar o direito penal, sozinho, para esse fim. Na verdade, a política criminal aplicada seria acompanhada de outros tipos de políticas. Por exemplo, nas palavras de Rawls, garante-se essa justiça socioeconômica não pela redistribuição 
de renda àqueles com menos, ao fim de cada período, mas, sim, garantindo-se "a difusão da propriedade de recursos produtivos e de capital humano (isto é, educação e treinamento de capacidades)", ${ }^{30}$ "ajustando-se para cima ou para baixo o nível de renda isento do imposto proporcional sobre a renda", ${ }^{31}$ adotando-se um imposto proporcional aos gastos: "um imposto sobre o consumo conforme uma taxa marginal constante." ${ }^{2}$ O governo tentou fazer algo parecido com o novo plano de segurança pública - chamado de Programa Nacional de Segurança Pública com Cidadania (Pronasci) -, por meio do qual tentou aumentar os estoques de bens das pessoas em situação de risco infracional, ${ }^{33}$ valendo-se, para tanto, de uma bolsafamília específica.

A política criminal, nessa lógica, também não seria usada com a finalidade de moldar preferências, dado que, em relação à idéia de bens primários, Rawls preocupa-se com as necessidades dos cidadãos, "em oposição a preferências, desejos e fins últimos". ${ }^{34}$ As transferências de bens no mercado devem pressupor o bem como valor de uso e não como valor de troca. Por isso, a transferência, exemplificada acima, seria justa, apesar de ineficiente ou injusta aos olhos utilitaristas.

\section{Conclusões}

É possível observar, em face do exposto, que os critérios de bem-estar geral e de igualdade oferecem caminhos e resultados distintos voltados a uma política pública. Escolher um ou outro dependerá dos valores que o governo quer alocar. A opção valorativa determina o que é justo ou não para o tomador da decisão. Temos qualificações de "justiça" diferentes, dentro dos dois modelos considerados. Os resultados obtidos com a política pública podem ser justificados pelo agente público, com base em cada um desses modelos, indicado o norte valorativo adotado - o bem-estar total ou a igualdade. Os critérios de Pareto/Rawls e de Kaldor-Hicks/ Mill levam a resultados distintos, apesar de o segundo ser mais prático do que o primeiro.

\footnotetext{
${ }^{30}$ RAWLS, John. Justiça como eqüidade. São Paulo: M. Fontes, 2003. p. 197.

${ }^{31}$ Ibidem, p. 229.

${ }^{32}$ Ibidem, p. 228.

${ }^{33}$ O plano assim considera os jovens entre 15 e 29 anos de idade.

${ }^{34}$ RAWLS, op. cit., p. 200.
} 
No critério da igualdade, a justiça consiste na distribuição em que as pessoas são tratadas como iguais, e nega-se a existência de qualquer valor independente. Trata-se de uma perspectiva deontológica. No critério da utilidade total, o bem-estar geral é o valor independente, de modo que um arranjo que atenda ao bem-estar individual, em detrimento do bem-estar total, será tomado como injusto. Trata-se de uma perspectiva teleológica. O justo é interpretado como o maximizador do bem. ${ }^{35}$ Para o primeiro, a questão de justiça é uma questão de "eqüidade pessoa a pessoa, mais do que eqüidade de somas agregadas". Para o segundo, a questão de justiça é uma questão de equilíbrio, e o equilíbrio é impessoal. ${ }^{36}$

Os objetivos fundamentais positivamente anunciados do Estado brasileiro, constantes do art. $3^{\circ}$ da Constituição Federal, tais como "construir uma sociedade livre, justa e solidária" ou "promover o bem de todos", não apontam um norte valorativo definido que permita uma escolha segura quanto à tomada de decisão política entre os dois modelos. Ambos, à sua maneira, atingem, ou acreditam que atingem, tais objetivos. Todavia, o art. $1^{\circ}$ de nossa Lei Maior, ao anunciar os fundamentos do Estado, aponta para um norte em seu inciso III: a dignidade da pessoa humana. Tal inciso não permite que alguém possa ser usado como instrumento para a obtenção de quantidades agregadas de utilidade, em um cálculo relativo à elaboração de uma política pública.

Nesse sentido, a política criminal pode e deve ser usada para certas redistribuições de bens, desde que, em seus cálculos, considere as pessoas igualmente, uma a uma, mesmo que isso signifique perdas de bem-estar geral. Portanto, consideramos que o critério fornecido por Rawls, que desafia o critério tradicional do utilitarismo, constitui um instrumento valioso para a concepção de uma política criminal, e que, por reafirmar um dos fundamentos do Estado brasileiro, poderia e deveria ser levado a sério por qualquer tomador de decisão política.

35 "O utilitarismo é uma teoria teleológica ao passo que a justiça como eqüidade não o é. Por definição, portanto, a segunda é uma teoria deontológica, que ou não especifica o bem independentemente do justo, ou não interpreta o justo como maximizador do bem. [...] A justiça como eqüidade é uma teoria deontológica no segundo sentido". RAWLS, John. Uma teoria da justiça. 2. ed. São Paulo: M. Fontes, 2002. p. 32.

${ }^{36}$ DWORKIN, Ronald. Uma questão de princípio. 2. ed. São Paulo: M. Fontes, 2005. p. 407. O equilíbrio é "impessoal" porque os indivíduos tornam-se instrumentos para a obtenção de quantidades agregadas de utilidade. 


\section{Guiding values for the elaboration of criminal politics: general welfare and equality}

\section{Abstract}

The objective of the present work is to draw an argumentative exercise about the guiding values for the elaboration of public politics. Considering two criteria found in political philosophy and in political economy - the values of general welfare and equality, present in John Stuart Mill's utilitarism and in John Rawl's theory of justice, respectivelly -, the article intends to analyse the different ways both guiding values can orient a criminal politics.

Key words: Welfare. Equality. Efficiency. Justice. Criminal politics.

\section{Referências}

DWORKIN, Ronald. The original position. In: DANIELS, Norman (Edit.). Reading Rawls: critical studies on Rawls'A theory of justice. California: Stanford University Press, 1975. . Uma questão de princípio. 2. ed. São Paulo: M. Fontes, 2005.

HARRISON, Jeffrey L. Law and economics in a nutshell. 2. ed. Florida: West Group, 2000.

LAHERA, Eugenio. Política y políticas públicas. Brasília: CEPAL, 2004. (Série Políticas Sociales, n. 95).

MILL, John Stuart. Utilitarismo. São Paulo: M. Fontes, 2000.

MONTESQUIEU. O espírito das leis. Brasília: Universidade de Brasília, 1995.

RUA, Maria das Graças. Análise de políticas públicas: conceitos básicos. In: RUA, Maria das Graças; CARVALHO, Maria Izabel V. (Org.). O estudo da política: tópicos selecionados. Brasília: Paralelo 15, 1998.

RAWLS, John. Uma teoria da justiça. 2. ed. São Paulo: M. Fontes, 2002. . Justiça como eqüidade. São Paulo: M. Fontes, 2003. 
SEN, Amartya. Desenvolvimento como liberdade. São Paulo: Cia das Letras, 2000.

ZAFFARONI, Eugenio R.; PIERANGELI, José H. Manual de direito penal brasileiro: parte geral. 4. ed. São Paulo: Revista dos Tribunais, 2002.

\section{Agradecimento}

Agradeço ao Prof. Dr. Frederico Barbosa pelos valiosos comentários sobre o texto. 
